\title{
The limits of law in the protection of public health and the role of public health ethics
}

Robyn Martin ${ }^{1}$

${ }^{1}$ Professor of Public Health Law, Centre for Research in Primary and Community Care, University of Hertfordshire

\section{Introduction}

This paper examines ways in which the legal concepts of duty and power might be used for the benefit of the public health, and the role of public health ethics in relation to these duties and powers. The discussion is placed within a framework of risk regulation. Risk is a notion which has been much examined in social science and epidemiology but until recently, has not been a concept which law has addressed to any real degree. A quick glance at government websites suggests that contemporary government in the United Kingdom is preoccupied with the notion of risk, and in particular regulatory frameworks

for the assessment of risk. ${ }^{1}$ The concept of risk has now entered into our legal vocabulary to enable new kinds of public duties, creating the potential for using risk regulation as a public health legal tool.

\section{Law and the notion of duty}

Traditional approaches to duty in law

For the purposes of this discussion I will assume 'duty' to mean an obligation which has a correlative the right or claim of another to ensure that the obligation is carried out. ${ }^{2}$ Law is the most powerful tool we have for the articulation and imposition of duties. Legal duties can be imposed on public bodies, private bodies and individuals. They can be 
enforced by a range of remedies, including criminal sanctions, civil liability, licensing or abatement. Legal duties can be imposed by statute, by regulations under statute or by the common law.

The more straightforward and specific the duty, the more efficacious the law is in stating, managing and enforcing the duty. For example under the Public Health (Ships) Regulations 1979, the master of a ship must notify the port authority of any suspected infectious disease or death on board ship, and this report must be made not more than 12 hours and not less than 4 hours before arriving in port. This is a simple duty, with no discretion, no ambiguity, and of course no reference to ethics. Law overrides autonomy, privacy, and individual rights.

More often though, duties cannot be so precisely defined and contain exercises of discretion. Section 52 of the Health and Safety at Work Act 1974 states that, 'It shall be the duty of every employer to ensure, so far as is reasonably practicable, the health, safety and welfare at work of his employees'. Under the National Health Service Act 1977, it is the duty of the Secretary of State to provide, to such extent as he considers necessary to meet all reasonable requirements, services such as medical and dental healthcare provision. Inherent within these duties is a requirement that a body or an individual make a judgment call on what is required to satisfy the duty. Typically however, legislation does not address assessment criteria. Rarely was it acknowledged in the parliamentary debate which led to the passing of laws, even where the word risk was used, that what was required was an assessment of risk. Interpretation of what is required to satisfy the duty has been left to the courts.

The Court of Appeal considered the legal meaning of risk in relation to the duty imposed by Section 3 of the Health and Safety at Work Act in the Science Museum case. ${ }^{3}$ The Act states that it shall be the duty of every employer to conduct his undertaking in such a way as to ensure, so far as is reasonably practicable, that persons not in his employment are not thereby exposed to risks to their health or safety. The museum was prosecuted when 
they failed to maintain their air conditioning system. Such failure might result in a risk of Legionnaires Disease. No evidence was brought to show that anyone had inhaled Legionnaires Disease. Had the museum exposed persons to risks to their health?

The Court suggested that 'risk' differs from 'danger', and gave an example. Imagine a loose object on a roof near a pavement. That loose object constitutes a risk. If the object falls towards the pavement, at that point there is a danger. If the object hits someone on the pavement, that constitute a harm. A risk is something that contains the possibility of danger. So the existence of unhealthy water in the air cooling system was like the object on the roof, it presented a risk. The Museum was therefore guilty of an offence under the Act.

This was not exactly a sophisticated analysis, but it does represent the beginning of the engagement of law, both at legislative and at judicial level, with the notion of risk. We could also note that social scientists have since expressed similar views on the meaning of risk. Giddens for example notes that:

' ...we must separate risk from hazard or danger. Risk is not, as such, the same as hazard or danger. A risk society is not intrinsically more dangerous or hazardous than pre-existing forms of social order - life in the Middle Ages was hazardous but there was no notion of risk. ${ }^{4}$

Gidden's analysis differs from that of the Court of Appeal however in that he acknowledges that risk cannot be assessed without recognizing values. 'There is no risk which can even be described without reference to a value', values such as how people might choose to live their lives, and what risks they are prepared to take in exchange for access to what benefits. If the risk of Legionnaire's disease cannot be eliminated from air conditioning systems, should we close down public museums to eliminate the risk? Or are there values in the existence of museums that we might be prepared to weigh against the risks?

The base line of risk acceptability differs from context to context. ${ }^{5}$ For health and safety legislation the norm is 'as far as reasonably practicable'. ${ }^{6}$ Pollution legislation tends to 
use guidelines such as 'best available technique not exceeding excessive cost' ${ }^{7}$ The Department of Health in relation to medicines uses a higher threshold level of 'no observable adverse effects' ${ }^{8}$ The levels of acceptable risk vary not in response to differing quantitative measurement but rather because in different contexts different values come into play. Those values are often debatable. A terminal cancer patient may well be prepared to take a risk higher than 'no observable adverse effect' for the opportunity to take experimental but potentially life extending drugs.

\section{A new type of legal duty}

Acts such as the Health and Safety at Work Act represent old style legislative approaches to standard setting. In recent years we have see a new generation of legislation which has more overtly adopted the language of risk. The Management of Health and Safety at Work Regulations 1999 state: 'Every employer shall make a suitable and sufficient assessment of the risks to the health and safety of his employees to which they are exposed while they are at work...for the purpose of identifying the measures he needs to take...'. ${ }^{9}$ The Control of Substances Hazardous to Health Regulations 2002 state that 'an employer shall not carry out any work which is liable to impose an employee to any substances hazardous to health unless he has.... made a suitable and sufficient assessment of the risk ... and of the steps that need to be taken...'. ${ }^{10}$ The Civil Contingencies Act 2004 imposes duties on specified public bodies 'from time to time to assess the risk of an emergency occurring'.

In this new kind of regulation there is overt recognition that the duty is not just a duty to assess the actual level of risk but also to assess what is an acceptable level of risk. These are enforceable legal duties and any breach will have serious consequences for the duty holder. It is a requirement of good law that it can be understood by those required to obey it. Determination of what is acceptable will require some scientific and probability analysis, and probably some form of economic cost/benefit analysis. It will also require a determination of what we as a society are prepared to accept in the way of risks to 
achieve the industrial or health benefits which flow from the risk creating activity. That of course is a question about values.

\section{Risk and public health}

It has been said by Beck ${ }^{11}$ among others that we now live in a 'risk society', a society of technological complexity that absolutely no-one completely understands, and which gives rise to a range of possible futures. Unlike earlier societies which accepted the future as fate, a risk society is 'preoccupied by the future' and wishes to explore it in order to control it ${ }^{12}$.

More importantly we now face a new kind of risk. Earlier societies which lived according to tradition were preoccupied with what Giddens has called external risk, risk of events outside our control but which are predictable, such as storms, earthquakes, plagues, bad harvests, diseases. There is no responsibility for preventing these external risks, only for dealing with the consequences of risk, and increasingly the state tended to take a paternalistic responsibility for risk consequences. The National Health Service and the welfare state were developed in response to risk. As the HM Treasury risk portal states, 'Governments have always had a critical role in protecting their citizens from risk'. ${ }^{13}$

Legislation provided the regulatory form of this paternalistic political commitment. Very detailed duties were imposed by legislation, in which the state determined the acceptable level of risk and set out legal duties accordingly.

Over time the type of risk we face has changed and has become closer to what Giddens categorises as manufactured risk, risk which we have ourselves have created through the expansion of science and technology. Having historically taken on responsibility to protect its citizens from risk, governments cannot now argue that in this new risk environment they have no risk management responsibility. Indeed the less that individuals understand about the technology which drives their environment, and the less individuals feel in control of their environment, the more they are looking to governments to manage risk. Risk management in our contemporary society is no easy task. Over manage and the state is accused of scaremongering and infringement of human rights; 
under manage and the government is accused of negligence and bowing to economic forces. Recent governments have adopted a dual strategy in relation to risk responsibility; both to embrace responsibility and to delegate it.

An example of embracement is the government's Risk Programme ${ }^{14}$ which states that government departments need to ensure 'further embedding of risk in the core processes of government'. The government sees itself firstly as a risk regulator with responsibility for legislating legal duties and standards, secondly in a stewardship role in relation to industrial risks, and thirdly as responsible for the identification and management of risks

At the same time there has been a concerted effort to delegate risk both up and down. Delegation up has primarily been to European level where there has developed a very significant body of directives, treaties and conventions, particularly around new technologies, by which the EU has taken responsibility for determining acceptable levels of risk.

Delegation down has taken three forms: the creation of regulatory bodies to manage risk, delegation to the private sector; and delegation to the individual.

The Health Protection Agency is an example of a regulatory body. It is a nondepartmental public body set up to advise and support the Department of Health. The Health Protection Agency Act ${ }^{15}$ and Management Statement ${ }^{16}$ give considerable emphasis to the role of the HPA in risk management. Another such regulatory body is the Health and Safety Executive, which has as its function 'responsibility for the regulation of almost all the risks to health and safety arising from work activity in Britain’:

'In our role as a regulator and with powers of discretion, the assessment of risk that we undertake' requires us to... 'go beyond the confines of the undertaking and look at the impact of our proposed action on society'. ${ }^{17}$

Delegation to the private sector is reflected in health and safety legislation requiring employers and industry to make assessments about risks to health from their activities. This is not an open-ended risk assessment. These risk assessments focus on the prospect 
of harm to individuals within the parameters of the legislation. Delegation to the individual can be seen in the Department of Health White Paper, Choosing Health, ${ }^{18}$ which suggests that 'People's lifestyles decisions are personal ones and they do not want Government to take responsibility away from them'. 'We (the government) will bring together messages that raise awareness of health risks with information about action that people can take themselves to address those risks’.

Wherever the legal duty lies, recognising the process as one of risk assessment enables the inclusion of qualitative risk factors in the determination of levels of acceptability of risk. This will require consideration of factors such as whether the risk is voluntary or involuntary, value judgments in the measurement of risks against benefits, and health inequalities - who has real choices about risk taking. Risk assessment needs also to take cognisance of who bears health risks and who takes the benefit of those risks, and the patterns of distribution of risk across society.

\section{Public health law}

Much law with relevance for public health such as environmental law and occupational health law has been subject to recent reform and has been developed to recognise both the role of risk assessment in the protection of health and the allocation of clear responsibilities for the process of assessment. However our core public health legislation remains untouched by the concerns of the risk society.

The duties set out in the Public Health Act 1984, which is not a 1984 Act as such but a consolidation of $19^{\text {th }}$ century legislation, are of the simple, paternalistic kind. There are duties on medical practitioners to notify the local authority in relation to specified notifiable diseases; duties on landlords to disinfect lodgings, duties on individuals not to expose others to specified diseases; duties in relation to the disposal of dead bodies and duties in relation to canal boats. These duties are inflexible. They cannot be used for new and unforeseen threats to health and they allow for little discretion in their application. Yet they may well place the duty holder in a position of conflict in relation to other duties 
such as duties of confidentiality, duties in relation to discrimination, or duties to respect human rights.

Legislation could provide duties in relation to the protection of public health such that they are sufficiently flexible to protect against unpredictable threat, and such that impositions of duty take into account other duties, values and the context of their application. If we were to take duties of notification for example, we could require in our legislation that public health officials make risk assessments as to which health threats warrant notification. The way law is currently framed, there is a non discretionary duty to notify particular notifiable diseases, and no legal duty to notify other threats to public health.

New Zealand is undertaking major reform of its public health law and has issued a consultation paper on law reform which proposes a different approach to notification. ${ }^{19} \mathrm{~A}$ general obligation would provide that any condition, disease, risk factor or other matter of public health concern be reported to the relevant authority. A 'condition', the paper explains, is a broader concept than disease, and would include matters such as clusters of symptoms and post-disease abnormalities. Guidance would be given in the regulations as to what particular issues warrant being notifiable at a given time and these regulations would be sufficiently flexible to take account of newly emerging public health threats. The paper proposes that legislation be drafted in an 'empowering style', to ensure, through means that respect privacy as far as possible, the availability of accurate, comprehensive and timely information on risk factors of public health significance, and of factors contributing to trends in incidence of adverse health conditions.

Public health law reforms in other jurisdictions have also proposed redesigning law to recognize the risk assessment component of public health duties. The discussion paper on reform of public health law in Western Australia ${ }^{20}$ suggests that law should take 'a new approach driven by risk', and that 'the new Health Act should be driven by the philosophy of minimizing risk to the public's health'. The paper proposes publishing policies and guidelines detailing risk assessment criteria to assist in the exercise of public health duties and powers. 
Most significantly the proposed laws in these jurisdictions would make clear the value framework of public health legislation, listing fundamental principles that would guide any exercise of discretion. Principles governing New Zealand law would recognize the rights and values in contemporary NZ: personal autonomy, freedom, privacy and human dignity, justice, equality, community, well being and interdependence. The Western Australian discussion paper notes that 'there is a strong case for new public health legislation to incorporate a set of objects that will direct the Act', and proposes a range of underpinning principles including sustainability, personal liberty and the precautionary principle.

These are principles familiar to us all but not as issues of law. They are rather principles of ethics, principles which have been considered as secondary, to be consulted when there are gaps in the law. In the reform proposals these principles would be embedded in law to assist in providing an explicit methodology for assessing risks to public health. Other jurisdictions have also reformed their public health legislation to recognize risk and to make clear that the exercise of law must take place within a framework of ethics.

Spanish health law ${ }^{21}$ states in its preamble:

The aim of this bill is to set out a legal framework for the co-ordination and cooperation of the public health authorities in the exercise of their respective functions in order to guarantee equity, quality and social participation...'

There is enormous potential for the use of risk regulation in public health. Law which recognises that much public health practice constitutes an exercise of risk assessment would reflect the realities of public health, providing a more useful public health tool. We could look to developments in environmental law as a way forward, but the most important starting point would be to include in our legislation a statement of the values and principles which we agree as a framework for public health practice to provide a framework in which risk assessment decisions are to be made.

\section{Law and the notion of power}


I will take as a shorthand definition of power that to say someone has a legal power is to assert that others thereby have a legal obligation to act, or not act, in certain ways. ${ }^{22}$ Coercive powers have always constituted a major tool in public health law. English ${ }^{23}$ public health legislation contains a range of coercive powers including powers of entry into premises, powers of compulsory medical examination and powers of compulsory detention. Powers by their very nature carry with them an element of discretion.

Under S. 36 of the Public Health Act 1984 there is power to order compulsory medical examination if

- there is reason to believe that one of a groups of persons, though not suffering from a notifiable disease, is carrying an organism that is capable of causing it

and

- that in the interests of those persons or their families, or in the public interest, it is expedient that those persons should be medically examined.

Exercise of this power requires a risk assessment, although the law is not framed in the language of risk. Similar powers of compulsory examination and detention also exist in relation to mental illness. While there has been significant scholarship around the nature of the risk assessment in the exercise of powers over persons lacking legal capacity, little attention has been given to the role of risk assessment in relation to public health powers. Challenge of mental health powers has resulted in a rethinking of both the processes and the philosophy of powers to infringe the autonomy and liberty of individuals, acknowledging the inherent risk assessment role. The Scottish consultation paper on mental health law $^{24}$ recommended the inclusion in legislation of criteria for determining the extent to which a person may be at risk or present a risk to others. The resulting legislation ${ }^{25}$ makes clear the ethics principles which are to govern this risk assessment exercise. In this new type of law, there is no tension between the exercise of compulsory 
legal powers on the one hand, and protection of rights, autonomy and dignity on the other. Ethics are embedded in the exercise of law, such that failure to consider ethics makes the exercise of law invalid. Could we frame public health law to bring rights and ethics into the fold of public health powers?

The starting point would be to reject the medicalisation of public health debate which pits hard science in the form of probability and objectively collated disease data, against the soft sciences of philosophy, sociology and ethics. Rather we would recognise that a power is an assertion of a moral claim of priority of particular values, for example that the health of the population has moral precedence over the freedom of movement of an individual with infectious disease. The importance of stating the ethics and values within the legal framework of the power then becomes clear.

Recognising that public health powers are about asserting moral claims, we can look again to the risk assessment inherent in the exercise of a power, not as a matter of measurement but as a matter of balancing moral considerations. We need to be clear about what moral considerations we, in our culture and in our time, consider to be relevant to the debate.

Again we can turn to the New Zealand proposals. Compulsory powers in the proposed NZ public health law would fall under the umbrella of 'Care and Management' both of persons with communicable disease who pose a risk to others, and persons who are infirm and neglected', who pose a risk to themselves. We can see a different philosophy here. Whereas the compulsory powers under our Public Health Act are to be exercised for the benefit of the healthy, and propose only exclusion and not care of the infectious person, the NZ proposals work from a starting point that public health officials owe duties of care to both the healthy and the ill.

The guiding principle of exercise of NZ powers would be 'the least restrictive alternative' ${ }^{26}$ Exercise of compulsory powers under our Public Health Act is also subject to the doctrine of 'least restrictive alternative', not in the legislation itself but externally, through the European Convention for the Protection of Human Rights. The European 
Court of Human Rights, in a case against the Swedish government in relation to legislation similar to our own ${ }^{27}$, found that the detention of a person who was HIV positive was an infringement of his human rights, in part because it was not the least restrictive way to deal with the risk. Our Public Health Act, unlike the Swedish legislation, has no lesser restrictive alternative powers. We have no legislative powers of compulsory counseling, treatment or quarantine.

The compulsory powers to made available under NZ legislation would range from compulsory counseling, compulsory supervision, through quarantine and detention, to compulsory treatment. The overarching decision would be one of risk assessment: were there 'reasonable grounds to consider that the person presents a significant health risk to the general public' in accordance with the principles of values and ethics stated in the legislation. This risk assessment framework provides mechanisms for achieving a balance between the need to deal with threats to population health, and the protection of the rights and the dignity of the individual, recognizing ascending levels of intervention to correspond with ascending levels of risk.

\section{Limits of our current public health law}

There are many ways in which our current public health law fails to deliver in providing a legal framework for public health protection. Our law is premised on the assumption that public health law serves to protect the healthy, and its primary mechanism is exclusion of the ill, who are often in the case of communicable disease the most vulnerable members of society. Our law fails to provide clear objectives for the exercise of the law, or to make clear the lines of responsibility for public health protection. It fails to make clear that public health legislation is about risk regulation, and does not provide risk assessment criteria. Our law is inflexible in that it fails to provide mechanisms for emerging risks to health. Most importantly our law puts public health officials in a position of conflict between the exercise of public health powers and duties on the one hand, and principles of ethics and human rights on the other. 
Law is only one tool in the protection of the public health. Traditionally it has been understood that law does the compulsory things, and ethics provide a framework for good practice. Until the development of domestic human rights law, which brought some but not all essential ethics principles into the legal fold, ethics remained a desirable but unenforceable framework for practice.

By adopting the language and scholarship of risk into law, we can incorporate the principles of ethics which underpin law. There will be no universal, international agreement of what those principles should be. They will depend on our cultural values. Asian or African societies for example may well choose different ethics principles favouring protection of the community over autonomy and individual rights. ${ }^{28} \mathrm{We}$ cannot emulate reforms in other jurisdictions for our public health law reform. We need to make our own call on our underlying principles and philosophies. We can however emulate them in marrying law and ethics in a framework of risk regulation.

\section{Conclusion}

Law has traditionally been seen as positivist, to be drafted as clearly as possible and to include little discretion. This old style of law has not proved sufficiently flexible or sufficiently sensitive to operate effectively in the domain of public health. We have been prompted to address the issue of public health law reform by concern about new and unpredictable infectious diseases, and by the reform of the International Health Regulations. These pressures provide an opportunity to think about what we could provide in the way of legal support for public health practice.

We have much detailed law which has relevance to health, such as law on food, the environment and occupational health. What we do not have is an umbrella piece of legislation which sets out our overall public health objectives, our public health priorities, or our public health guiding principles. We need legislation which makes clear what we consider to be our primary public health functions and law which allocates responsibility for those functions. We need legislation that makes clear our public health values, so that we can make decisions on issues of acceptability of risk, recognising that public health 
practice is an exercise in risk assessment. We need legislation that is as much concerned with the care of those who are ill as with protecting the healthy. We have an opportunity to build ethics into the framework of public health law. Good public health practice needs good law, and good law is ethical law. We should bear this in mind in our process of public health law reform.

1 The Department of Health website has a portal on risk research and has published on-line documents on risk (see Department of Health. Communicating About Risks to Public Health. 1999; Department of Health. Risk Literature and the Public. 1993). The HM Treasury site has a Risk Programme, a 'comprehensive programme of change to improve risk management across government' (December 2003), as well as a portal on risk guidance. The Health and Safety Executive has a portal for its publications on risk.

2 See Hohfeld WN. Fundamental Legal Conceptions. ed Cook WW. New Haven and London: Yale University Press; 1919

${ }^{3} R v$ Board of Trustees of the Science Museum [1993] ICR 876

${ }^{4}$ Giddens A. Risk and Responsibility. Modern Law Review 1999; 62(1): 1-10, 3

${ }^{5}$ Fisher E. Drowning by Numbers: Standard Setting in Risk Regulation and the Pursuit of Accountable Public Administration. Oxford Journal of Legal Studies. 2000; 20(1): 109-130

${ }^{6}$ Health and Safety Executive. Reducing Risks, Protecting People. 1999

7 Pollution Prevention and Control Act 1999

${ }^{8}$ Intergovernmental Liaison Group on Risk Assessment. Use of risk Assessment in Government Departments 1999; 15-19

${ }^{9}$ Section 3

10 Section 6

11 Beck U. Risk Society: Towards a New Modernity. London: Sage; 1992

12 Giddens A. Risk and Responsibility. Modern Law Review 1999; 62(1): 1-10, 3

${ }^{13} \mathrm{http}: / /$ www.hm-treasury.gov.uk

${ }^{14}$ HM Treasury. The Risk Programme: Improving Government's Risk Programme. Final Report to the Prime Minister. December 2004

${ }^{15}$ Health Protection Act 2004

${ }^{16}$ Health Protection Agency. Management Statement. January 2004

17 Health and Safety Executive. Reducing Risks and Protecting People. 1999

${ }^{18}$ Department of Health. Choosing Health: Making healthy choices easier. 2004

${ }^{19}$ Ministry of Health New Zealand. Public Health Legislation: Discussion Paper. Promoting Public Health, Preventing Ill Health and Managing Communicable Diseases. November 2002

${ }^{20}$ Department of Health, Western Australia. New Public Health Act for Western Australia: A Discussion Paper. June 2005

${ }^{21}$ Spanish National Health System Cohesions and Quality Act 2003

22 See Dworkin R. Taking Rights Seriously. London: Duckworth; 1981

${ }^{23}$ Scotland and northern Ireland have similar powers

${ }^{24}$ New Directions - Report on Review of the Mental Health (Scotland) Act. 1999

${ }^{25}$ Mental Health (Care and Treatment) Act 2003. As well as looking to medical evidence, the person exercising the power must consider principles of non-discrimination, equality, respect for diversity, informal care, participation, respect for carers, least restrictive alternatives, benefit and child welfare. 
${ }^{26}$ Western Australian proposed reforms also recommend incorporating the principle of 'least restrictive alternative' into the legislation.

${ }^{27}$ Enhorn $v$ Sweden [2005] ECHR 56529/00. See Martin R. The exercise of public health powers in cases of infectious disease: Human rights implications. Medical Law Review 2006; 14(1) 132-143

${ }^{28}$ Philippine public health legislation of 1999 begins with a public health mandate which includes: the promotion of the health and well-being of every Filipino, the prevention and control of diseases among populations at risk, the protection of individuals and families exposed to hazards and risks that could affect their health, and the treatment of individuals at risk. Philippine law prioritises compulsory treatment powers over personal autonomy.

\title{
Commentary on The limits of law in the protection of public health law and the role of public health ethics.
}

\author{
Angus Dawson ${ }^{1}$ \\ ${ }^{1}$ Director of the Centre for Professional Ethics, University of Keele.
}

Any adequate account of 'public health' should contain at least three key features. ${ }^{28}$ The first is that the focus of public health interventions is upon a population of unspecified individuals. Second, public health action requires collective effort in the sense that improvements in public health cannot be brought about by any single individual acting alone. This is one reason why much public health activity must be, as Gostin suggests, the preserve of the state. Third, public health activity is primarily focused on reducing or eliminating the risk of harm. This is why public health interventions can be contentious. It may be that the disagreement is about whether the risk is real (an epistemic dispute) or it might be over whether the risk provides sufficient justification for interference in other people's lives (an ethical dispute). A vital aspect of this ethical dispute arises from the fact that much public health activity is concerned with the prevention of harms. For this to be the basis of policy, judgments need to be made about what sort of things are harmful, and such judgments in turn can only be made against a background theory of what it is to lead a good life. A common (and plausible) feature of such a background 
theory will be that health is important, and factors that interfere with it, should be prevented or removed. Water fluoridation to reduce dental caries, vaccination against infectious disease, banning smoking in public places, might all be justified by such a conception of the 'good life'.

Law played a significant role in relation to public health through the great reforms of the mid-nineteenth century. These statutes, particularly the Public Health Acts, provided the framework for vigorous intervention in response to the threat from contagious disease in an age with poor social conditions and without the aid of preventive measure such as vaccination, ${ }^{28}$ and are the backbone of present day public health powers. Martin subjects these to astute criticism. The relevant statues are very specific in the sense that they name particular diseases and particular types of establishment. They give permission for certain interventions, and provide for compulsion in some cases. This approach is flawed in that the degree of specification means that new threats to health remain outside of their scope until government chooses to add them to the list of specified diseases. Such a statutory approach has the advantage of clarity and arguably ensures the greatest transparency where restrictions in liberty or the requisitioning of property are necessary. However, this also provides a basis for critics to argue that public health can be too easily tempted to sacrifice the interests of the individual for the common good. ${ }^{28}$

Martin considers more recent developments in the law relevant to public health: first, the growth of discretionary powers, second, the new kind of statutory regulation that more explicitly uses the language of risk and, thirdly, the role of public health ethics. Can these developments provide sufficient support for public health activity to meet the objections above?

Firstly, talk of risk of harm as well as actual harm is helpful in thinking about public health. This is because much public health is concerned with reducing or preventing risks to health. This means we can take a step away from waiting until harm is caused and then 
seeking compensation. Discretionary powers such as those discussed in the Science Museum case can mean that an individual or body might be found liable for a failure to remove a risk of harm, even if no one was actually harmed. ${ }^{28}$ This idea might be applied to public health.

Secondly, where 'the [relevant] duty is not just a duty to assess the level of risk but also to assess what is an acceptable level of risk', the relevant individual or body with the particular duty to deliberate about the nature of the risk is placed under a more rigorous burden. This again is helpful as the focus moves away from the question is the risk sufficiently likely to happen?' Instead the focus is on a judgment of 'acceptability' of that risk as well as its likelihood. This requires a range of issues to be taken into account relating to the possible risks and benefits of the intervention, including an unavoidable role for normative values. What counts as 'acceptable' is likely to change over time so the relevant duty will impose the need for constant review. As Martin illustrates, this opens up the possibility of acrimonious debate about the nature of risk and the sorts of risks that are acceptable. On a more positive note, there is no reason why such assessment of risk cannot include preventive action. On the face of it, an 'unacceptable' risk might result from the failure to take action. For example, a failure to promote routine childhood vaccination for serious contagious diseases increases the risk of harm. This suggests that it might well be possible to have a public health statute that would impose duties to promote public health, not just seek to remove threats once they have emerged.

The most original aspect of Professor Martin's paper is her consideration of the role that public health ethics, or values more generally, might play in public health law. This is a natural step once we see that values are necessary in any deliberations about action in response to risk. I offer two cautions to this approach here.

The first is that the area of ethics is a minefield of contested theories and principles. The law must take care as it chooses a path through this danger. Perhaps the dominant approach in contemporary bioethics is a form of liberalism derived mainly from the work 
of Mill and Feinberg. ${ }^{28}$ This approach fits very well with the traditional common law. However, is such liberalism useful when it comes to public health? I am sceptical. What we need in public health is an ethical approach that is familiar with and accepting of the concepts of prevention and collective action. It is unclear whether classical liberalism can incorporate such notions into its view of the world. This does not, however, necessarily require a defence of one particular moral theory as such concepts may be defended using a range of theories such as consequentialism, contractarianism, and republicanism, but also certain forms of deonotology focused on prima facie duties. ${ }^{28}$ It is an advantage if law can remain (relatively) neutral about which approach is best.

The second caution is in relation to the way the courts are likely to treat any ethical and pragmatic principles. There will always be a tendency towards reification of principles, as jurisprudence is built up around them. Even the principle of 'the least restrictive alternative' might actually be insufficiently flexible. Such a principle seems to suggest that we should always prioritise liberty over other values. However, is it clear that we should? This looks like a background commitment to liberalism that in turn needs to be justified. Respecting people's autonomy is an important ethical principle, but it is only one amongst many. ${ }^{28}$ Banning smoking in public places restricts people’s autonomy, but it may be justified by appealing to the idea that in this case other values take priority. Such a ban might be justified by arguing that it is a means of positively promoting health, particularly a population’s health.

What is most important in thinking about ethics in relation to public health is that the ethics are relevant to public health practice. Public health is about population health; therefore the focus must be on the interventions that can make a difference to improving the population's health as a whole. Most interventions of this type require collective action. One important way to justify such interventions is through an appeal to the idea of public goods. We can think of public goods, following Klosko, as being characterised by two main properties: nonexcludability and dependence upon cooperation by a large number of people. ${ }^{28}$ 'Nonexcludable goods' are those where no one can be excluded from the 
benefits of the existence of the relevant good, even when they have not contributed towards bringing it about. In addition to these two aspects of public goods suggested by Klosko I would add another proposed by Rawls. ${ }^{28}$ Public goods must also be indivisible: that is, they cannot be broken down or divided up into individual or private goods to be distributed amongst the members of a group or population. ${ }^{28}$

The creation and maintenance of such public goods may well result in inconveniences or injustices in relation to some individuals, but this may still be justified given the benefits. For example, a population where fewer people smoke is a better place for children to grow up. A ban on smoking in public is only justifiable if these values take priority over the individual liberties of smokers. Public health activity is involved in many such contentious activities. The important thing is that such interventions can be justified in at least some cases. Where this is the case, the law may play an important role in attempting to reduce or remove risks to health.

Public health is an important issue. Governments can do a lot to influence and improve a population's public health. The law is one, although not the only, means of action. ${ }^{28}$ Law has had a troubled relationship with public health, but we can see some hopeful signs for the future. One aspect of this is the broader conception of what is relevant to deliberation about risk, and another is the explicit consideration of values within public health law. Both developments are welcome as they allow the reality of public health work to be reflecting in the legal framework. However, public health law needs to be careful to reflect actual public health practice and ensure that the concept of prevention is given adequate legal support.

\footnotetext{
${ }^{28}$ For discussion of the first two issues, see: Verweij, M. \& Dawson, A. "The meaning of "public" in public health' in Dawson, A. \& Verweij, M. (eds.) Ethics, Prevention, and Public Health. Oxford: OUP (forthcoming).

${ }^{28}$ Except, of course, for smallpox.

${ }^{28}$ See the sometimes brutal debate over the US Model Emergency Powers Act in, for example, Hodge, JG \& Gostin, LO 'Protecting the public's health in an era of bioterrorism: the Model State Emergency Health Powers Act' and Annas, G. 'Terrorism and human rights', both in Moreno, JD. (ed.) (2003) In the Wake of Terror: Medicine and Morality in a Time of Crisis. Cambridge, Mass: Bradford Book/MIT Press.
} 
${ }^{28} R v$ Board of Trustees of the Science Museum [1993] ICR 876.

${ }^{28}$ See, for example, Mill, JS. (1859) On Liberty. Reprinted 1974. Harmondsworth: Penguin, Feinberg, J. (1973) Social Philosophy. Engelwood Cliffs, NJ: Prentice-Hall and Feinberg, J. (1984) Harm to Others. Oxford: Oxford University Press.

${ }^{28}$ See Bayer, R. \& Fairchild, AL. (2004) 'The genesis of public health ethics', Bioethics, 18, 6: 473492; Scanlon, TM. (2000) What we owe to each other. Harvard: Harvard University Press; Jennings, B. 'Public Health and Civic Republicanism: Toward an Alternative Framework for Public Health Ethics' in Dawson, A. \& Verweij, M. (eds.) Ethics, Prevention, and Public Health. Oxford: OUP (forthcoming); Ross, WD. The Right and the Good Oxford: Clarendon Press, 1967.

${ }^{28}$ Dawson, A. \& Garrard, E. (2006) In defence of moral imperialism: four equal and universal prima facie duties. Journal of Medical Ethics 32, 4: xxx.

${ }^{28}$ Klosko, G. (1987) Presumptive benefit, fairness and political obligation. Philosophy and Public Affairs. 16, 3: 241-259: 242-3.

${ }^{28}$ Rawls (1971) A Theory of Justice. Oxford: Oxford University Press.

${ }^{28}$ For more on public goods, see Dawson, forthcoming, op cit.

${ }^{28}$ See Lawrence O. Gostin's essay in this series 'Legal Foundations of Public Health Law and its Role in Meeting Future Challenges' for some discussion

\section{Commentary on The limits of law in the protection of public health law and the role of public health ethics.}

Angus Dawson ${ }^{1}$

${ }^{1}$ Director of the Centre for Professional Ethics, University of Keele.

Any adequate account of 'public health' should contain at least three key features. ${ }^{28}$ The first is that the focus of public health interventions is upon a population of unspecified individuals. Second, public health action requires collective effort in the sense that improvements in public health cannot be brought about by any single individual acting alone. This is one reason why much public health activity must be, as Gostin suggests, the preserve of the state. Third, public health activity is primarily focused on reducing or eliminating the risk of harm. This is why public health interventions can be contentious. It may be that the disagreement is about whether the risk is real (an epistemic dispute) or it might be over whether the risk provides sufficient justification for interference in other 
people's lives (an ethical dispute). A vital aspect of this ethical dispute arises from the fact that much public health activity is concerned with the prevention of harms. For this to be the basis of policy, judgments need to be made about what sort of things are harmful, and such judgments in turn can only be made against a background theory of what it is to lead a good life. A common (and plausible) feature of such a background theory will be that health is important, and factors that interfere with it, should be prevented or removed. Water fluoridation to reduce dental caries, vaccination against infectious disease, banning smoking in public places, might all be justified by such a conception of the 'good life'.

Law played a significant role in relation to public health through the great reforms of the mid-nineteenth century. These statutes, particularly the Public Health Acts, provided the framework for vigorous intervention in response to the threat from contagious disease in an age with poor social conditions and without the aid of preventive measure such as vaccination, ${ }^{28}$ and are the backbone of present day public health powers. Martin subjects these to astute criticism. The relevant statues are very specific in the sense that they name particular diseases and particular types of establishment. They give permission for certain interventions, and provide for compulsion in some cases. This approach is flawed in that the degree of specification means that new threats to health remain outside of their scope until government chooses to add them to the list of specified diseases. Such a statutory approach has the advantage of clarity and arguably ensures the greatest transparency where restrictions in liberty or the requisitioning of property are necessary. However, this also provides a basis for critics to argue that public health can be too easily tempted to sacrifice the interests of the individual for the common good. ${ }^{28}$

Martin considers more recent developments in the law relevant to public health: first, the growth of discretionary powers, second, the new kind of statutory regulation that more explicitly uses the language of risk and, thirdly, the role of public health ethics. Can these 
developments provide sufficient support for public health activity to meet the objections above?

Firstly, talk of risk of harm as well as actual harm is helpful in thinking about public health. This is because much public health is concerned with reducing or preventing risks to health. This means we can take a step away from waiting until harm is caused and then seeking compensation. Discretionary powers such as those discussed in the Science Museum case can mean that an individual or body might be found liable for a failure to remove a risk of harm, even if no one was actually harmed. ${ }^{28}$ This idea might be applied to public health.

Secondly, where 'the [relevant] duty is not just a duty to assess the level of risk but also to assess what is an acceptable level of risk', the relevant individual or body with the particular duty to deliberate about the nature of the risk is placed under a more rigorous burden. This again is helpful as the focus moves away from the question 'is the risk sufficiently likely to happen?' Instead the focus is on a judgment of 'acceptability' of that risk as well as its likelihood. This requires a range of issues to be taken into account relating to the possible risks and benefits of the intervention, including an unavoidable role for normative values. What counts as 'acceptable' is likely to change over time so the relevant duty will impose the need for constant review. As Martin illustrates, this opens up the possibility of acrimonious debate about the nature of risk and the sorts of risks that are acceptable. On a more positive note, there is no reason why such assessment of risk cannot include preventive action. On the face of it, an 'unacceptable' risk might result from the failure to take action. For example, a failure to promote routine childhood vaccination for serious contagious diseases increases the risk of harm. This suggests that it might well be possible to have a public health statute that would impose duties to promote public health, not just seek to remove threats once they have emerged.

The most original aspect of Professor Martin's paper is her consideration of the role that public health ethics, or values more generally, might play in public health law. This is a 
natural step once we see that values are necessary in any deliberations about action in response to risk. I offer two cautions to this approach here.

The first is that the area of ethics is a minefield of contested theories and principles. The law must take care as it chooses a path through this danger. Perhaps the dominant approach in contemporary bioethics is a form of liberalism derived mainly from the work of Mill and Feinberg. ${ }^{28}$ This approach fits very well with the traditional common law. However, is such liberalism useful when it comes to public health? I am sceptical. What we need in public health is an ethical approach that is familiar with and accepting of the concepts of prevention and collective action. It is unclear whether classical liberalism can incorporate such notions into its view of the world. This does not, however, necessarily require a defence of one particular moral theory as such concepts may be defended using a range of theories such as consequentialism, contractarianism, and republicanism, but also certain forms of deonotology focused on prima facie duties. ${ }^{28}$ It is an advantage if law can remain (relatively) neutral about which approach is best.

The second caution is in relation to the way the courts are likely to treat any ethical and pragmatic principles. There will always be a tendency towards reification of principles, as jurisprudence is built up around them. Even the principle of 'the least restrictive alternative' might actually be insufficiently flexible. Such a principle seems to suggest that we should always prioritise liberty over other values. However, is it clear that we should? This looks like a background commitment to liberalism that in turn needs to be justified. Respecting people's autonomy is an important ethical principle, but it is only one amongst many. ${ }^{28}$ Banning smoking in public places restricts people’s autonomy, but it may be justified by appealing to the idea that in this case other values take priority. Such a ban might be justified by arguing that it is a means of positively promoting health, particularly a population’s health.

What is most important in thinking about ethics in relation to public health is that the ethics are relevant to public health practice. Public health is about population health; 
therefore the focus must be on the interventions that can make a difference to improving the population's health as a whole. Most interventions of this type require collective action. One important way to justify such interventions is through an appeal to the idea of public goods. We can think of public goods, following Klosko, as being characterised by two main properties: nonexcludability and dependence upon cooperation by a large number of people. ${ }^{28}$ 'Nonexcludable goods' are those where no one can be excluded from the benefits of the existence of the relevant good, even when they have not contributed towards bringing it about. In addition to these two aspects of public goods suggested by Klosko I would add another proposed by Rawls. ${ }^{28}$ Public goods must also be indivisible: that is, they cannot be broken down or divided up into individual or private goods to be distributed amongst the members of a group or population. ${ }^{28}$

The creation and maintenance of such public goods may well result in inconveniences or injustices in relation to some individuals, but this may still be justified given the benefits. For example, a population where fewer people smoke is a better place for children to grow up. A ban on smoking in public is only justifiable if these values take priority over the individual liberties of smokers. Public health activity is involved in many such contentious activities. The important thing is that such interventions can be justified in at least some cases. Where this is the case, the law may play an important role in attempting to reduce or remove risks to health.

Public health is an important issue. Governments can do a lot to influence and improve a population's public health. The law is one, although not the only, means of action. ${ }^{28}$ Law has had a troubled relationship with public health, but we can see some hopeful signs for the future. One aspect of this is the broader conception of what is relevant to deliberation about risk, and another is the explicit consideration of values within public health law. Both developments are welcome as they allow the reality of public health work to be reflecting in the legal framework. However, public health law needs to be careful to reflect actual public health practice and ensure that the concept of prevention is given adequate legal support. 
${ }^{28}$ For discussion of the first two issues, see: Verweij, M. \& Dawson, A. "The meaning of "public" in public health' in Dawson, A. \& Verweij, M. (eds.) Ethics, Prevention, and Public Health. Oxford: OUP (forthcoming).

${ }^{28}$ Except, of course, for smallpox.

${ }^{28}$ See the sometimes brutal debate over the US Model Emergency Powers Act in, for example, Hodge, JG \& Gostin, LO 'Protecting the public's health in an era of bioterrorism: the Model State Emergency Health Powers Act' and Annas, G. 'Terrorism and human rights', both in Moreno, JD. (ed.) (2003) In the Wake of Terror: Medicine and Morality in a Time of Crisis. Cambridge, Mass: Bradford Book/MIT Press.

${ }^{28} R v$ Board of Trustees of the Science Museum [1993] ICR 876.

28 See, for example, Mill, JS. (1859) On Liberty. Reprinted 1974. Harmondsworth: Penguin, Feinberg, J. (1973) Social Philosophy. Engelwood Cliffs, NJ: Prentice-Hall and Feinberg, J. (1984) Harm to Others. Oxford: Oxford University Press.

28 See Bayer, R. \& Fairchild, AL. (2004) 'The genesis of public health ethics', Bioethics, 18, 6: 473492; Scanlon, TM. (2000) What we owe to each other. Harvard: Harvard University Press; Jennings, B. 'Public Health and Civic Republicanism: Toward an Alternative Framework for Public Health Ethics' in Dawson, A. \& Verweij, M. (eds.) Ethics, Prevention, and Public Health. Oxford: OUP (forthcoming); Ross, WD. The Right and the Good Oxford: Clarendon Press, 1967.

${ }^{28}$ Dawson, A. \& Garrard, E. (2006) In defence of moral imperialism: four equal and universal prima facie duties. Journal of Medical Ethics 32, 4: xxx.

${ }^{28}$ Klosko, G. (1987) Presumptive benefit, fairness and political obligation. Philosophy and Public Affairs. 16, 3: 241-259: 242-3.

${ }^{28}$ Rawls (1971) A Theory of Justice. Oxford: Oxford University Press.

${ }^{28}$ For more on public goods, see Dawson, forthcoming, op cit.

${ }^{28}$ See Lawrence O. Gostin's essay in this series 'Legal Foundations of Public Health Law and its Role in Meeting Future Challenges' for some discussion 